in vivo $32: 1137-1144(2018)$

doi:10.21873/invivo.11356

\title{
Antitumor Ability of KT2 Peptide Derived from Leukocyte Peptide of Crocodile Against Human HCT116 Colon Cancer Xenografts
}

\author{
PORNSUDA MARAMING ${ }^{1 *}$, SURACHAI MAIJAROEN ${ }^{2 *}$, SOMPONG KLAYNONGSRUANG $^{2}$, \\ PATCHAREE BOONSIRI ${ }^{3}$, SAKDA DADUANG $^{4}, \mathrm{JING}^{-G U N G ~ C H U N G}{ }^{5}$ and JUREERUT DADUANG ${ }^{6}$ \\ ${ }^{1}$ Biomedical Sciences Program, Graduate School, ${ }^{2}$ Protein and Proteomics Research Center for Commercial and \\ Industrial Purposes (ProCCI), Department of Biochemistry, Faculty of Science, ${ }^{3}$ Department of Biochemistry, \\ Faculty of Medicine, ${ }^{4}$ Division of Pharmacognosy and Toxicology, \\ Faculty of Pharmaceutical Sciences, Khon Kaen University, Khon Kaen, Thailand; \\ ${ }^{5}$ Department of Biological Science and Technology, College of Biopharmaceutical and Food Sciences, \\ China Medical University, Taichung, Taiwan, R.O.C.; \\ ${ }^{6}$ Centre for Research and Development of Medical Diagnostic Laboratories, \\ Faculty of Associated Medical Sciences, Khon Kaen University, Khon Kaen, Thailand
}

\begin{abstract}
Background/Aim: Many antimicrobial peptides have been shown to have anticancer activity against human cancer cell lines. Cationic KT2 peptide, derived from white blood cell extract of Crocodylus siamensis has antibacterial activity and antitumor activity against human cervical cancer cells, but there are no data on the effect of KT2 peptide on tumor growth in vivo. The anticancer activity of KT2 peptide on human colon cancer xenografts was investigated in nude mice. Materials and Methods: Tumors in nude mice $(B A L B / c-n u / n u$ mice) were induced by subcutaneous injection with HCT116 cells. Twelve days after cancer cell xenograft, mice were treated by intratumoral injection with phosphate-buffered saline or KT2 peptide $(25$ and $50 \mathrm{mg} / \mathrm{kg}$ ) once every 2 days for a total of four times and mice were sacrificed at 2 days after the last treatment. Results: KT2 peptide treatment did not lead to significant difference in mouse body weight among groups, but reduced both tumor volume and weight of colon cancer xenografts. Moreover, KT2 peptide increased the expression of apoptotic
\end{abstract}

This article is freely accessible online.

*These Authors contributed equally to this work.

Correspondence to: Dr. Jureerut Daduang, Centre for Research and Development of Medical Diagnostic Laboratories, Faculty of Associated Medical Sciences, Khon Kaen University, Khon Kaen, 40002, Thailand. Tel/Fax: +66 43202088, e-mail: jurpoo@kku.ac.th

Key Words: Colorectal cancer, anticancer activity, KT2 peptide, xenograft, apoptosis. proteins, such as BCL2-associated $X$ (BAX), cleaved caspase-3, and poly (ADP-ribose) polymerase and reduced that of BCL2 apoptosis regulator in xenograft tumors. Conclusion: This finding suggests that KT2 peptide may inhibit tumor growth via apoptosis induction in this mouse model and supports the antitumor ability of KT2 peptide.

Naturally-occurring antimicrobial peptides (AMPs) are biological molecules acting in host defense against infection and are present in organisms from six kingdoms including bacteria, archaea, protists, fungi, plants, and animals (1). These AMPs have the broad-spectrum of properties against bacteria, yeasts, fungi, viruses and even cancer cells (2). AMPs display a net positive charge of +2 to +9 due to consisting of positively charged amino acids such as arginine, lysine and histidine, while they also contain a high ratio of nonpolar amino acids in general, result in binding of AMPs to negative charge on bacterial membranes $(2,3)$. The nonpolar part of an AMP allows insertion of the AMP molecule into the cell membrane, subsequently enabling cellular uptake of AMPs including through mechanisms such as direct penetration and endocytosis (4). Cancer cell membranes generally exhibit a net negative charge due to overexpression of anionic molecules (5). The negative surface charge characteristic of the cancer cell membrane is similar to that of bacterial cells, this is the main reason for studying the anticancer activity of AMPs (6). Another reason is that AMPs act mainly on the plasma membranes through a non-receptor-mediated mechanism, this route is difficult for tumor cells to develop drug resistance (7). According to the Antimicrobial Peptides Database of the Department of Pathology and Microbiology 


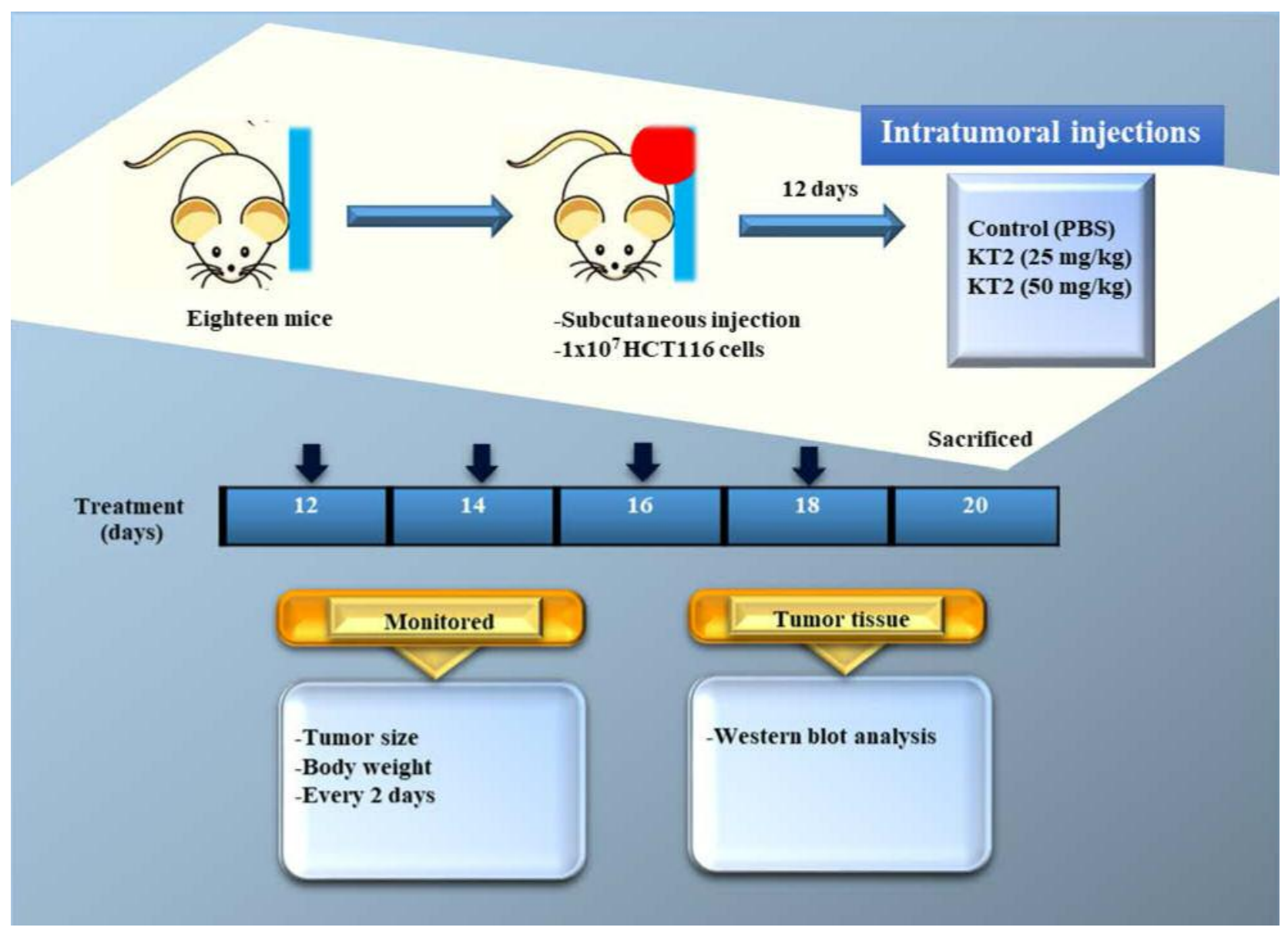

Figure 1. The flow chart for KT2 treatment in athymic BALB/c nu/nu nude mice after inoculation with HCT116 cells.

(http://aps.unmc.edu/AP/main.php), University of Nebraska Medical Center, 215 AMPs are anticancer peptides (ACPs). For instance, LL-37 (human cationic AMP) inhibits proliferation of AGS human gastric carcinoma cells by activation of tumor-suppressing bone morphogenetic protein signaling via proteasome inhibition (8), and also kills Jurkat human $\mathrm{T}$ leukemia cells via the mitochondria-associated pathway of apoptosis (9).

ACPs are believed to selectively kill cancer cells, but not normal cells or have less toxicity to normal cells (5). The plasma membrane of normal eukaryotic cells contains phosphatidylserine (PS), a negatively-charged phospholipid which is mostly expressed in the inner leaflet, while neutral zwitterionic phospholipids (phosphatidylcholine, phosphatidylethanolamine and sphingomyelin) are located mainly in the outer membrane leaflet (10). Conversely, PS is present in significant proportions in the outer leaflet of apoptotic and cancer cell membranes (11). The aberration in PS localization in cancer cells, as well as higher expression than that of normal cells of negative molecules such as heparin sulfate, sialylated gangliosides, and O-glycosylated mucins, increased transmembrane potential, surface area, and membrane fluidity, promote the attraction of cationic ACPs to the negatively charged molecules on outer plasma membrane of cancer cells and create a strong electrostatic interaction of ACPs with the target cells (12-15). On the binding of peptide to the cell surface, some cationic ACPs can penetrate through the hydrophobic core membrane into the cytosol and bind with biomolecules inside cells in order to inhibit nucleic-acid synthesis, protein synthesis, or enzymatic activity, ultimately leading to cytolysis $(15,16)$.

KT2, a cationic amphipathic AMP (seven positive charges, $53 \%$ hydrophobic residues), was first derived from crocodile leukocyte peptide of Crocodylus siamensis. Structural analysis by spectropolarimetry showed that KT2 has an $\alpha$-helical structure (17). It can kill both Gram-negative and Grampositive bacteria pathogens (17). Being cationic, KT2 can bind to negatively charged molecules (e.g. lipopolysaccharide and 
anionic phospholipids) on bacterial membranes. Their hydrophobic part helps them to penetrate across the membrane, thereby gaining entry into cells, subsequently binding to intracellular polynucleotides, leading to inhibition of macromolecular synthesis (18). A recent study demonstrated that KT2 can kill human cervical cancer cells via apoptosis induction (16). In the present study, we demonstrated the effects of KT2 peptide on human colon cancer cells (HCT116) using mouse xenograft models.

\section{Materials and Methods}

Chemicals and reagents. KT2 peptide ( $>95 \%$ purity; NGVQPK YKWWKWWKKWW-NH ${ }_{2}$ ) was obtained from GL Biochem Ltd (Shanghai, China). Primary and secondary antibodies for western blot analysis were purchased from Cell Signaling Technology, Inc. (Beverly, MA, USA) and Santa Cruz Biotechnology (Santa, Cruz, CA, USA). Cell culture reagents and supplements were purchased from Gibco by Life Technologies (Carlsbad, CA, USA). Eighteen female 4week-old BALB/cAnN.Cg-Foxn1nu/Crl Narl mice were obtained from the National Laboratory Animal Center (Taipei, Taiwan, ROC). The treatment protocols were approved by the Institutional Animal Care and Use Committee of China Medical University (Taichung, Taiwan, ROC) (approval ID: 2018-005).

HCT116 cell culture. HCT116 human colon cancer cell line (Food Industry Research and Development Institute, Hsinchu, Taiwan, ROC) was cultured in RPMI 1640 medium with supplementation (10\% fetal bovine serum, $100 \mathrm{units} / \mathrm{ml}$ penicillin, and $100 \mu \mathrm{g} / \mathrm{ml}$ streptomycin) at $37^{\circ} \mathrm{C}$ in a humidified incubator with $5 \% \mathrm{CO}_{2}$.

In vivo anticancer activity of KT2 peptide. The schematic depiction of the experimental protocol is shown in Figure 1. Eighteen female athymic $\mathrm{BALB} / \mathrm{c}$ nu/nu nude mice were injected subcutaneously with $1 \times 10^{7}$ HCT116 cells into the right flank and then randomly divided into three groups (each group=6). Twelve days after colon cancer cell injection, mice were treated by intratumoral injection with PBS or KT2 peptide once every 2 days for 8 days (four treatments). One group of mice was treated with PBS as control group and two groups were treated with the different doses of KT2 peptide ( 25 , or $50 \mathrm{mg} / \mathrm{kg}$ body weight). Body weight and tumor size of mice were monitored once every two days. The formula [0.5 $(\mathrm{L} 1 \times \mathrm{L} 2 \times \mathrm{H})]$ was used for calculation of tumor volume where L1 was the longest tumor diameter, L2 the shortest diameter, and $\mathrm{H}$ the height of the tumor (19). Two days after the end of treatment, mice were anesthetized with Zoletil $50^{\circledR}$ (Virbac, Carros, France) and tumor tissues were removed, weighed and processed for western blotting of apoptosis-associated protein expression.

Western immunoblotting. Total protein was extracted from tumor tissues and its concentration was measured using Bio-Rad protein assay kit (Bio-Rad Laboratories, Hercules, CA, USA). Protein from each sample was separated on a $10-12 \%$ sodium dodecyl sulfate polyacrylamide gel electrophoresis and transferred onto polyvinylidene fluoride membranes (Millipore, Billerica, MA, USA) (20). The membranes were blocked with blocking buffer, then incubated with primary antibodies to $\beta$-actin, BCL2-associated X (BAX), BCL2 apoptosis regulator, caspase-3 and poly (ADP-ribose) polymerase (PARP) according to the manufacturer's instructions (Cell Signaling Technology). Membranes were then washed with $0.1 \%$ Tween 20 in

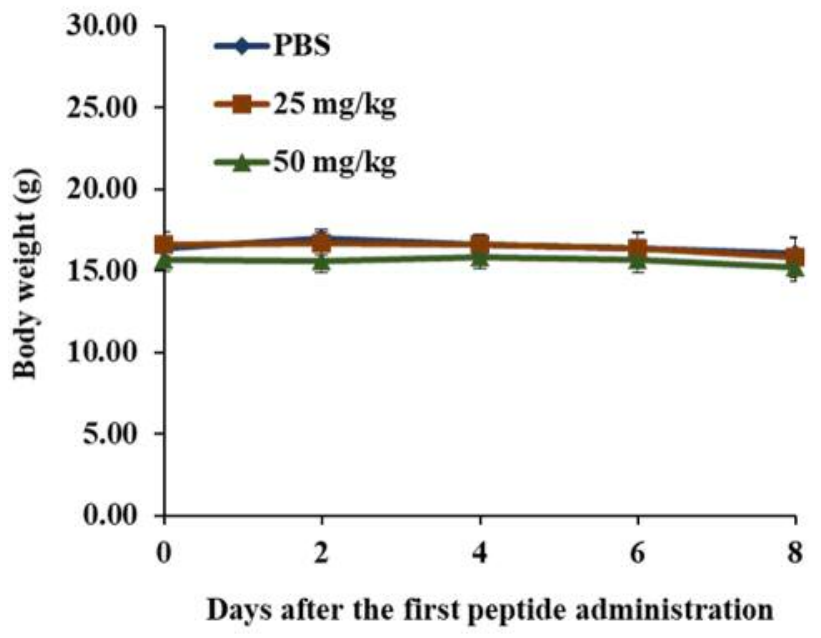

Figure 2. Body weights of athymic BALB/c nu/nu nude mice after inoculation with HCT116 cells. Eighteen mice were inoculated subcutaneously with HCT116 cells. Mice were randomly divided into three groups for treatment every 2 days. Group $I(n=6)$ was treated with phosphate-buffered saline (PBS). Group II $(n=6)$ was treated with KT2 $(25 \mathrm{mg} / \mathrm{kg})$. Group III $(\mathrm{n=})$ ) was treated with KT2 (50 mg/kg). Each mouse was treated by intratumoral injection for 8 days; the body weight was recorded every 2 days, as described in the Materials and Methods.

1X PBS, and followed by incubation with peroxidase labeled secondary antibody. The bands of protein were detected and quantified with ECL Western Blotting Substrate (Amresco., OH, USA) $(21,22)$.

Statistical analysis. All data are expressed as means \pm S.D. Student's $t$ test by SigmaPlot ver. 10 (SigmaPlot for Windows version 10.0; Systat Software, Inc., San Jose, CA) was used to determine differences of data from the experimental groups versus the control, and the results were considered significant when $p<0.05$.

\section{Results}

KT2 did not affect the body weight of athymic BLAB/c nu/nu nude mice bearing HCT116-derived tumors. The results shown in Figure 2 indicate that treatment with KT2 at 25 and $50 \mathrm{mg} / \mathrm{kg}$ did not lead to statistically significant differences in body weight of mice when compared to the control group, indicating no signs of acute or delayed toxicity.

KT2 inhibited HCT116 cell xenograft tumor growth in athymic $B L A B / c$ nu/nu nude mice. Mice treated with $50 \mathrm{mg} / \mathrm{kg} \mathrm{KT2}$ exhibited significantly smaller tumor volume at day 4 $(p<0.05)$, day $6(p<0.01)$, and day $8(p<0.01)$ after the first treatment (Figure 3A). The representative animal and tumors with or with KT2 treatment were shown in Figure 3B and C which indicated that KT2 treatment reduced the tumor volume when compared to control group and higher dose of KT2 (50 mg/2 days) have significantly reduced tumor weights than that of low dose of KT2 (25 mg/2 days) $(p<0.05)$ (Figure 3D). 


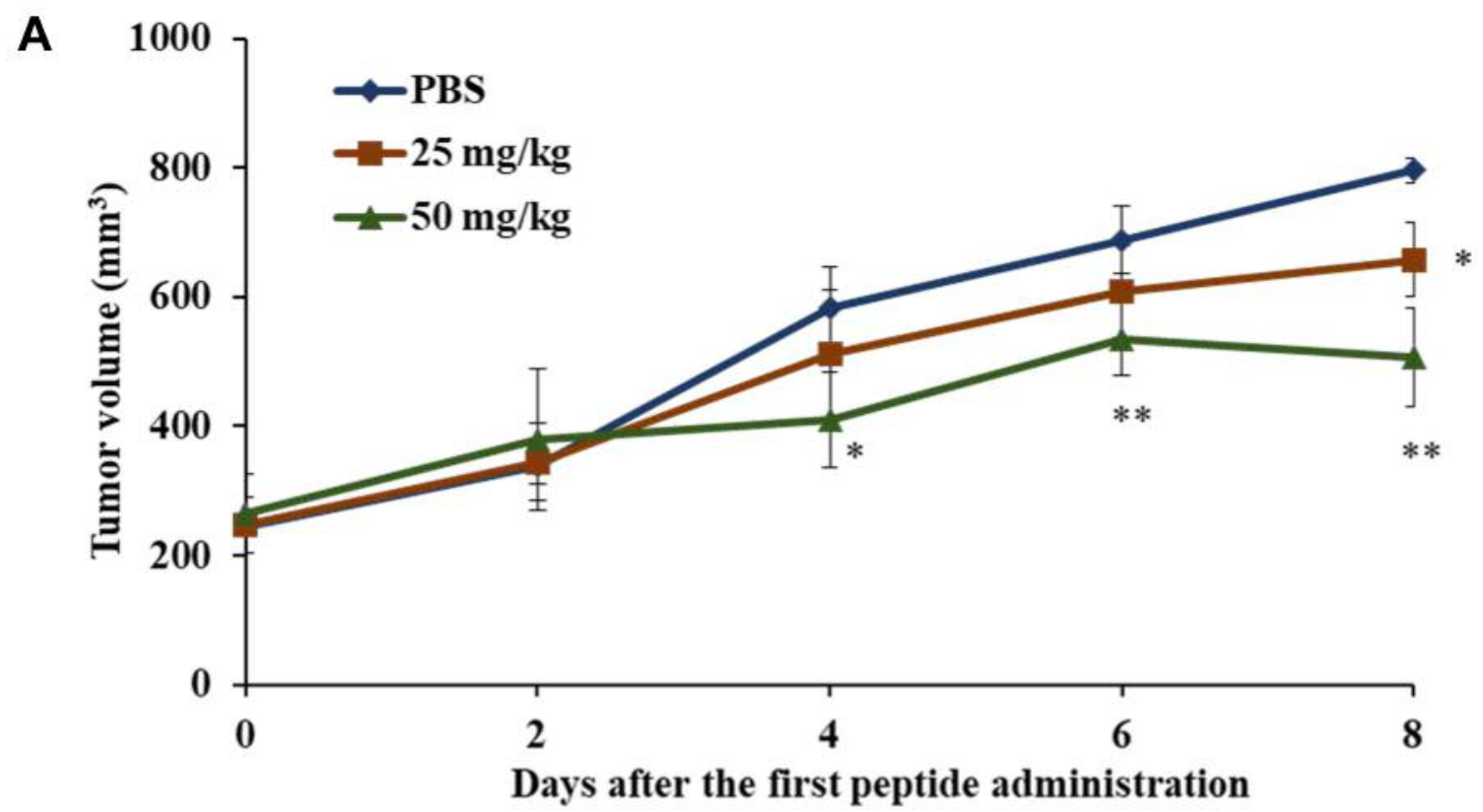

B
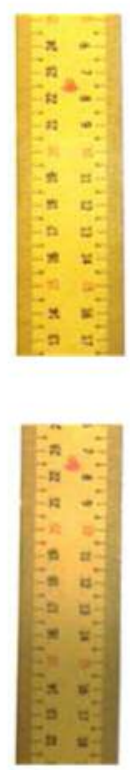

KT2 (mg/kg)

PBS

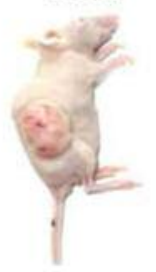

PBS

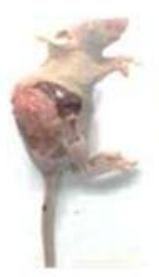

25

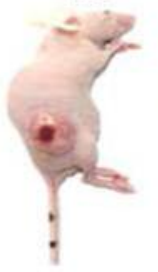

50

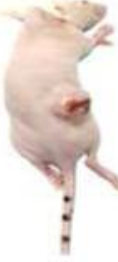

$\mathrm{KT} 2(\mathrm{mg} / \mathrm{kg})$
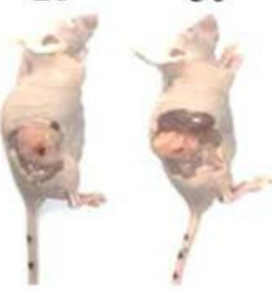

C

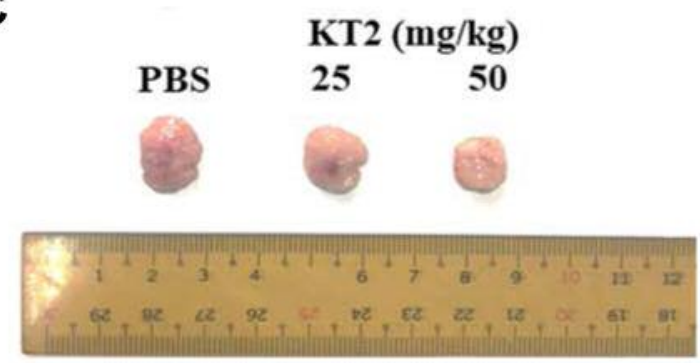

D

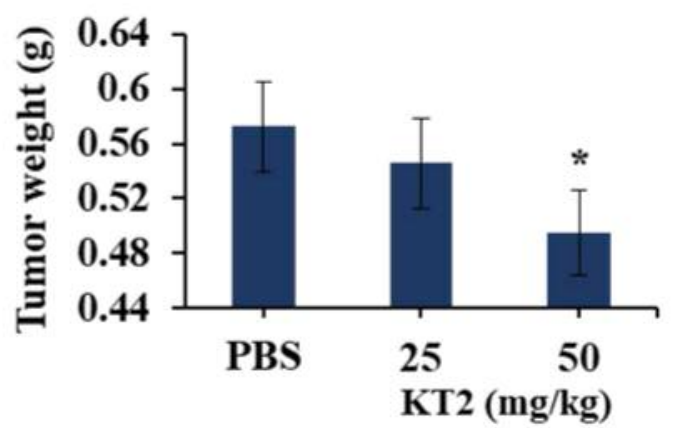

Figure 3. KT2 reduces HCT116 cell xenograft tumor growth in athymic BALB/c nu/nu nude mice. After HCT116 tumor-bearing mice were generated, mice were treated with KT2 (25 and $50 \mathrm{mg} / \mathrm{kg}$ ) or phosphate-buffered saline (PBS) every 2 days for 8 days. A: The tumor volume of each mouse was measured every two days. After mice were anesthetized using Zoletil $50^{\circledR}$, they were sacrificed and the final tumor weights were measured as described in the Materials and Methods. B: Images of representative mice with tumor from each group. C: Images of representative tumors from each group. D: Total tumor weights. *Significantly different at $p<0.05$ versus the control group. ${ }^{*}$ Significantly different at $p<0.1$ versus the control group.

KT2 affects the expression of apoptosis-related protein signal pathway of HTC 116 cell xenograft tumor cells. In an earlier study, we found that KT2 induced cytotoxic cell death through induction of apoptosis of HCT116 cells in vitro (data not shown). For fully evaluating the inhibition of KT2 treatment on HCT116 cell xenografts, tumors were collected from each animal to examine expression of apoptosisassociated protein by western blot. Results indicated that KT2 
A

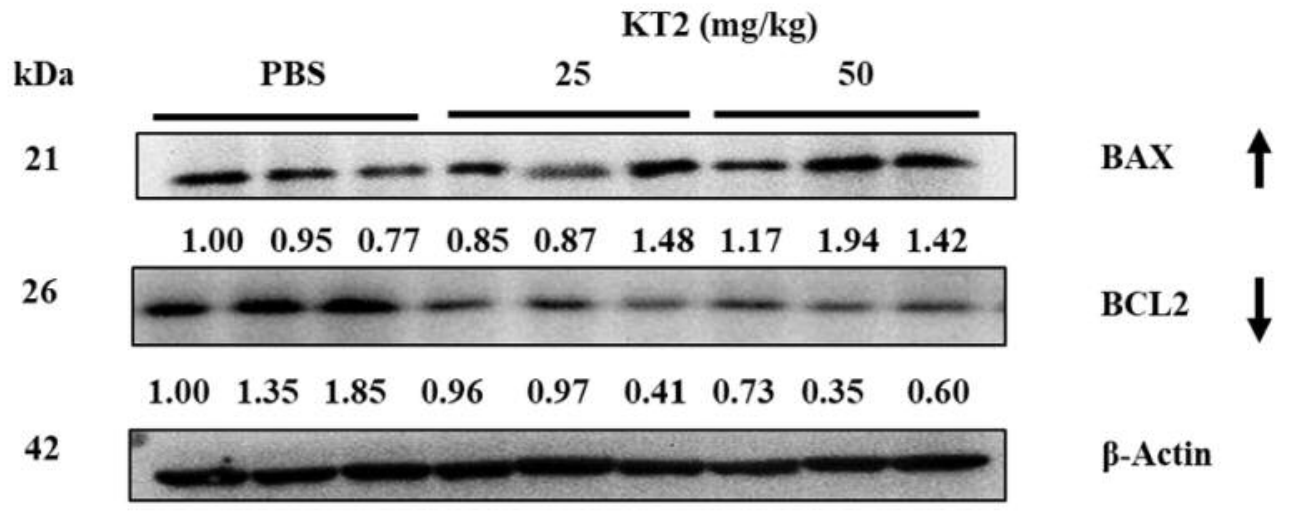

B

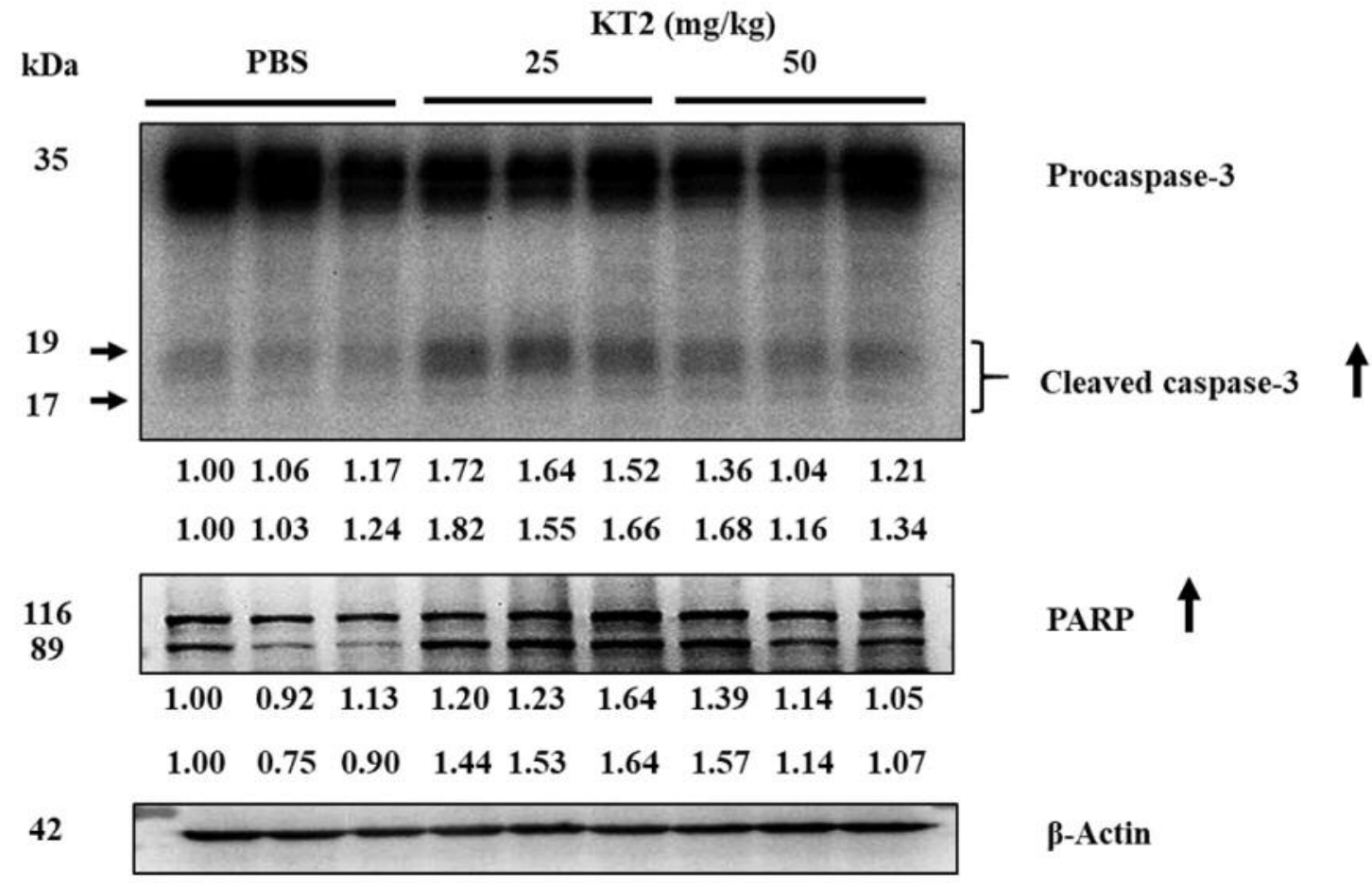

Figure 4. KT2 affects the expression of apoptosis-related proteins in HCT116 cell xenografts. After treatment, tumors were isolated from HCT116 cell xenografts and western blotting was performed as described in the Materials and Methods for $\beta$-actin, BCL2 apoptosis regulator (BCL2), BCL2-associated X (BAX), caspase-3 and poly (ADP-ribose) polymerase (PARP). PBS: Phosphate-buffered saline. The numbers under the gel electrophoresis were calculated from the normalization ratio of compound band density/beta-actin hand density.

increased the level of BAX and reduced that of BCL2 (Figure $4 \mathrm{~A}$ ), and increased cleavage of caspase- 3 and PARP (Figure 4B). Overall, these data demonstrated that KT2 suppressed tumor properties in vivo.

\section{Discussion}

Cationic AMP is still an attractive agent for cancer treatment to solve the problem of chemotherapy resistance and reduce toxicity to normal cells (23). Membranes of bacterial and cancer cells share the similarity of higher expression of negatively- charged molecules than normal cells (5). KT2 peptide has been reported to be able to kill bacteria (17). This led us to hypothesize that the cationic KT2 peptide may be able to destroy cancer cells. A previous study report that KT2 peptide induced apoptosis of HeLa human cervical cancer cells (16). Nevertheless, the anticancer activity of KT2 peptide has not been proven in mice. Animal models are important for the development of novel anticancer drugs and provide information on drug efficiency and safety assessment $(24,25)$.

We selected direct intratumoral injection of peptide into solid tumors based on the fact it may have better benefit than 


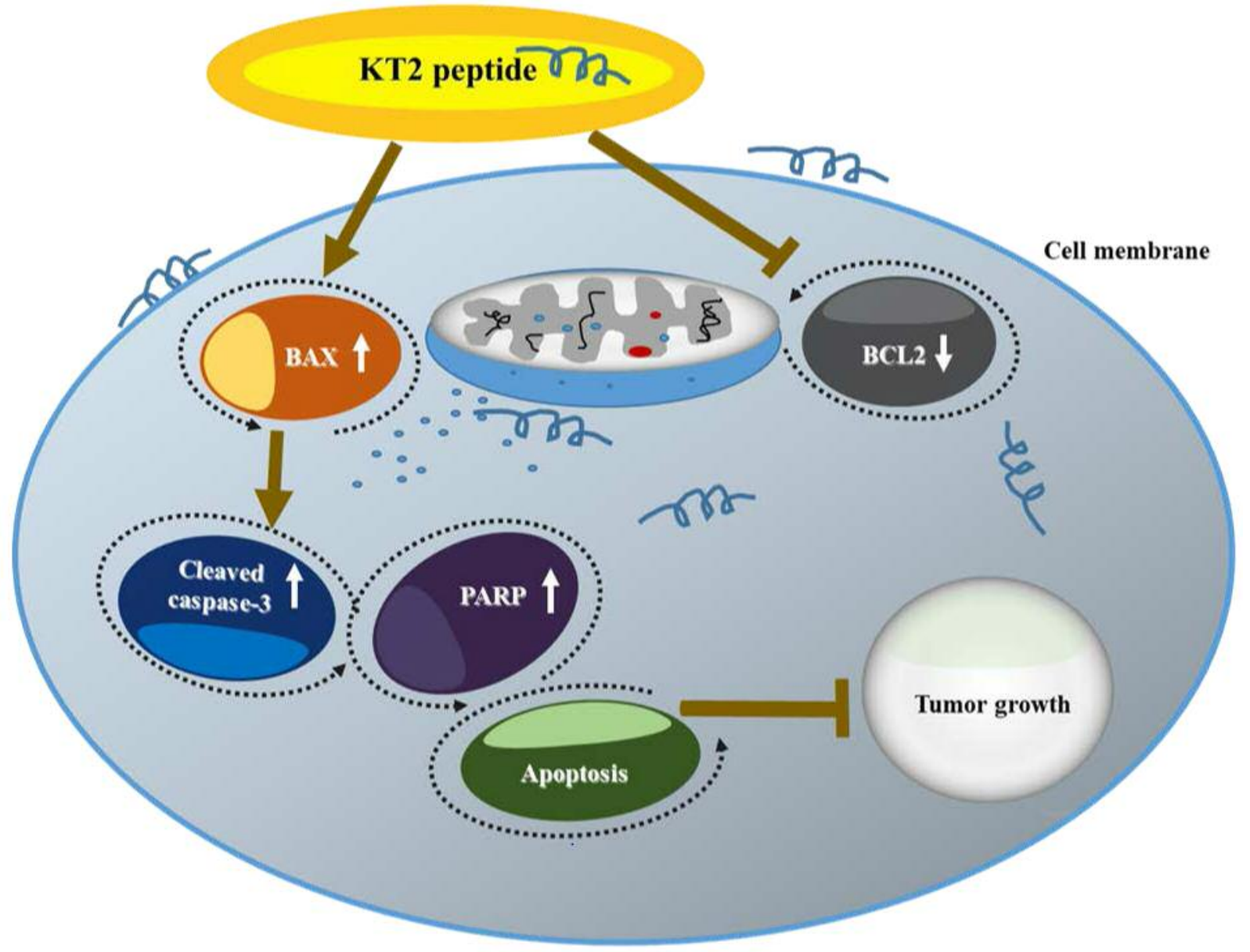

Figure 5. The potential mechanism for KT2-induced inhibition of tumor progression is through blockage of BCL2 apoptosis regulator (BCL2) and promotion of BCL2-associated X (BAX), caspase-3 cleavage and poly (ADP-ribose) polymerase (PARP) in vivo.

other routes of peptide injection due to reducing non-specific toxicity or unexpected immune response when administered systematically, and the effect of peptide on tumors is exhibited directly (26). Moreover, anticancer drug treatment via intratumoral injection can provide a high local drug level at the tumor site and improve drug effectiveness (27). Finally, intratumoral treatment may be especially beneficial for cancer that occurs in vital organs and which is difficult to treat systemically or surgically (28).

Several studies have been published on the antitumor role of AMPs against various human cancer cell lines in vitro; some AMPs were tested in mouse xenograft tumor systems (29-31). The intratumoral KT2 injections did not lead to differences in the body weight of animals. There were also no animal deaths, indicating a good safety profile. Our results showed that the weight and size of HCT116 cell tumors in nude mice were reduced after treatment with KT2 peptide. This shows that a short AMP with highly positively charged amino acids has an antitumor effect on a xenograft mouse model in agreement with a previous report (32). KT2 showed anticancer activity similarly to other cationic AMPs that were also reported as anticancer drugs in vitro and in vivo, such as lactoferricin B (33), LL-37 (34), PFR (peptide fragment derived from human lactoferricin) (35), and magainin II (36).

AMPs have been shown in various human cancer cell lines either to disrupt the cancer cell membrane or to penetrate the cell and affect mitochondria leading to apoptosis (23). For the study of protein expression level, we focused on apoptosis-associated proteins.

Western blot analysis results indicated that KT2 peptide inhibited tumor growth through induction of apoptosis. Apoptosis, a non-inflammatory form of programmed cell death, usually happens in cell development and aging is part of a negative feedback control system to maintain a dynamically balanced of cell population (37). KT2 increased 
pro-apoptotic BAX protein and reduced anti-apoptotic BCL2 protein (Figure 4A). It is well documented that the ratio of BAX to BCL2 reflects the state of the mitochondriaI membrane potential (38), a loss of which is associated with cell apoptosis (39). This phenomenon may lead to pore formation in the outer membranes of mitochondria, which are crucial organelles involved in the intrinsic pathway of cell apoptosis $(40,41)$. After mitochondrial pore formation, cytochrome $c$ is released from the mitochondria to the cytosol to initiate caspase activation, thereby inducing apoptosis (42). Herein, KT2 peptide was shown to increase cleavage of caspase-3 and PARP (Figure 4B); these two proteins are downstream in the apoptosis pathway (43). Figure 5 represents the mechanisms involved in inhibiting tumor growth upon KT2 treatment.

In conclusion, cationic KT2 peptide derived from leukocyte extract of $C$. siamensis did not significantly change the body weight of mice, but inhibited HCT116 xenograft tumor growth and appeared to induce apoptosis.

\section{Acknowledgements}

This work was supported by The Royal Golden Jubilee (RGJ) Ph.D Scholarship (PHD/0014/2558) with The National Research Council of Thailand (grant no. 2558), Khon Kaen University research grant (grant no. 61004605), the Centre for Research and Development of Medical Diagnostic Laboratories, Faculty of Associated Medical Sciences and Graduate School, Khon Kaen University.

\section{References}

1 Wang G, Li X and Wang Z: APD3: The antimicrobial peptide database as a tool for research and education. Nucleic Acids Res 44: D1087-1093, 2016.

2 Zhang LJ and Gallo RL: Antimicrobial peptides. Curr Biol 26: R14-19, 2016

3 Ren SX, Shen J, Cheng AS, Lu L, Chan RL, Li ZJ, Wang XJ, Wong CC, Zhang L, Ng SS, Chan FL, Chan FK, Yu J, Sung JJ, $\mathrm{Wu}$ WK and Cho CH: FK-16 derived from the anticancer peptide LL-37 induces caspase-independent apoptosis and autophagic cell death in colon cancer cells. PLoS One 8: e63641, 2013.

4 Bahar AA and Ren D: Antimicrobial peptides. Basel 6: 15431575, 2013.

5 Hoskin DW and Ramamoorthy A: Studies on anticancer activities of antimicrobial peptides. Biochim Biophys Acta 1778: 357-375, 2008.

6 Mader JS and Hoskin DW: Cationic antimicrobial peptides as novel cytotoxic agents for cancer treatment. Expert Opin Investig Drugs 15: 933-946, 2006.

7 Gaspar D, Freire JM, Pacheco TR, Barata JT and Castanho MA: Apoptotic human neutrophil peptide-1 anti-tumor activity revealed by cellular biomechanics. Biochim Biophys Acta 1853 : 308-316, 2015.

8 Wu WK, Sung JJ, To KF, Yu L, Li HT, Li ZJ, Chu KM, Yu J and Cho $\mathrm{CH}$ : The host defense peptide LL-37 activates the tumorsuppressing bone morphogenetic protein signaling via inhibition of proteasome in gastric cancer cells. J Cell Physiol 223: 178$186,2010$.
9 Mader JS, Mookherjee N, Hancock RE and Bleackley RC: The human host defense peptide LL-37 induces apoptosis in a calpain-and apoptosis-inducing factor-dependent manner involving BAX activity. Mol Cancer Res 7: 689-702, 2009.

10 Fadeel B and Xue D: The ins and outs of phospholipid asymmetry in the plasma membrane: Roles in health and disease. Crit Rev Biochem Mol Biol 44: 264-277, 2009.

11 Leite NB, Aufderhorst-Roberts A, Palma MS, Connell SD, Ruggiero Neto J and Beales PA: PE and PS lipids synergistically enhance membrane poration by a peptide with anticancer properties. Biophys J 109: 936-947, 2015.

12 Chen C, Yang C, Chen Y, Wang F, Mu Q, Zhang J, Li Z, Pan F, $\mathrm{Xu} \mathrm{H}$ and Lu JR: Surface physical activity and hydrophobicity of designed helical peptide amphiphiles control their bioactivity and cell selectivity. ACS Appl Mater Interfaces 8: 26501-26510, 2016.

13 Felicio MR, Silva ON, Goncalves S, Santos NC and Franco OL: Peptides with dual antimicrobial and anticancer activities. Front Chem 5: 5, 2017.

14 Schweizer F: Cationic amphiphilic peptides with cancerselective toxicity. Eur J Pharmacol 625: 190-194, 2009.

15 Hilchie AL, Doucette CD, Pinto DM, Patrzykat A, Douglas S and Hoskin DW: Pleurocidin-family cationic antimicrobial peptides are cytolytic for breast carcinoma cells and prevent growth of tumor xenografts. Breast Cancer Res 13: R102, 2011.

16 Theansungnoen T, Maijaroen S, Jangpromma N, Yaraksa N, Daduang $\mathrm{S}$, Temsiripong $\mathrm{T}$, Daduang $\mathrm{J}$ and Klaynongsruang $\mathrm{S}$ : Cationic antimicrobial peptides derived from Crocodylus siamensis leukocyte extract, revealing anticancer activity and apoptotic induction on human cervical cancer cells. Protein J 35: 202-211, 2016.

17 Anunthawan T, Yaraksa N, Phosri S, Theansungnoen T, Daduang S, Dhiravisit A and Thammasirirak S: Improving the antibacterial activity and selectivity of an ultra short peptide by hydrophobic and hydrophilic amino acid stretches. Bioorg Med Chem Lett 23: 4657-4662, 2013.

18 Anunthawan T, de la Fuente-Nunez C, Hancock RE and Klaynongsruang S: Cationic amphipathic peptides KT2 and RT2 are taken up into bacterial cells and kill planktonic and biofilm bacteria. Biochim Biophys Acta 1848: 1352-1358, 2015.

19 Li W, Gao F, Ma X, Wang R, Dong X and Wang W: Deguelin inhibits non-small cell lung cancer via down-regulating hexokinase II-mediated glycolysis. Oncotarget 8: 32586-32599, 2017.

20 Chiang JH, Yang JS, Ma CY, Yang MD, Huang HY, Hsia TC, Kuo HM, Wu PP, Lee TH and Chung JG: Danthron, an anthraquinone derivative, induces DNA damage and caspase cascade-mediated apoptosis in SNU-1 human gastric cancer cells through mitochondrial permeability transition pores and Baxtriggered pathways. Chem Res Toxicol 24: 20-29, 2011.

21 Ho CC, Huang AC, Yu CS, Lien JC, Wu SH, Huang YP, Huang HY, Kuo JH, Liao WY, Yang JS, Chen PY and Chung JG: Ellagic acid induces apoptosis in TSGH8301 human bladder cancer cells through the endoplasmic reticulum stress-and mitochondria-dependent signaling pathways. Environ Toxicol 29: 1262-1274, 2014.

22 Chiang JH, Yang JS, Lu CC, Hour MJ, Chang SJ, Lee TH and Chung JG: Newly synthesized quinazolinone HMJ-38 suppresses angiogenetic responses and triggers human umbilical vein endothelial cell apoptosis through p53-modulated Fas/death receptor signaling. Toxicol Appl Pharmacol 269: 150-162, 2013. 
23 Deslouches B and Di YP: Antimicrobial peptides with selective antitumor mechanisms: prospect for anticancer applications. Oncotarget 8: 46635-46651, 2017.

24 Kumar S, Bajaj S and Bodla RB: Preclinical screening methods in cancer. Indian J Pharmacol 48: 481-486, 2016.

25 Dahham SS, Hassan LE, Ahamed MB, Majid AS, Majid AM and Zulkepli NN: In vivo toxicity and antitumor activity of essential oils extract from agarwood (Aquilaria crassna). BMC Complement Altern Med 16: 236, 2016.

26 Liu Q, Zhao H, Jiang Y, Wu M, Tian Y, Wang D, Lao Y, Xu N and $\mathrm{Li} \mathrm{Z}$ : Development of a lytic peptide derived from BH3-only proteins. Cell Death Discov 2: 16008, 2016.

27 Park SH, Kim DY, Panta P, Heo JY, Lee HY, Kim JH, Min BH and Kim MS: An intratumoral injectable, electrostatic, crosslinkable curcumin depot and synergistic enhancement of anticancer activity. NPG Asia Materials 9: e397, 2017.

28 Chen RW, Braun GB, Luo XQ, Sugahara KN, Teesalu T and Ruoslahti E: Application of a proapoptotic peptide to intratumorally spreading cancer therapy. Cancer Res 73: 1352-1361, 2013.

29 Han Y, Cui Z, Li YH, Hsu WH and Lee BH: In vitro and in vivo anticancer activity of pardaxin against proliferation and growth of oral squamous cell carcinoma. Mar Drugs 14: 2, 2015.

30 Hanaoka Y, Yamaguchi Y, Yamamoto H, Ishii M, Nagase T, Kurihara $\mathrm{H}$, Akishita $\mathrm{M}$ and Ouchi $\mathrm{Y}$ : In vitro and in vivo anticancer activity of human beta-defensin-3 and its mouse homolog. Anticancer Res 36: 5999-6004, 2016.

31 Rodrigues EG, Dobroff AS, Cavarsan CF, Paschoalin T, Nimrichter L, Mortara RA, Santos EL, Fazio MA, Miranda A, Daffre $S$ and Travassos LR: Effective topical treatment of subcutaneous murine B16F10-Nex2 melanoma by the antimicrobial peptide gomesin. Neoplasia 10: 61-68, 2008.

32 Chu HL, Yip BS, Chen KH, Yu HY, Chih YH, Cheng HT, Chou YT and Cheng JW: Novel antimicrobial peptides with high anticancer activity and selectivity. PLoS One 10: e0126390, 2015.

33 Pan WR, Chen PW, Chen YLS, Hsu HC, Lin CC and Chen WJ: Bovine lactoferricin $\mathrm{B}$ induces apoptosis of human gastric cancer cell line AGS by inhibition of autophagy at a late stage. J Dairy Sci 96: 7511-7520, 2013.

$34 \mathrm{Wu}$ WKK, Wang GS, Coffelt SB, Betancourt AM, Lee CW, Fan $\mathrm{DM}$, Wu KC, Yu J, Sung JJY and Cho CH: Emerging roles of the host defense peptide LL-37 in human cancer and its potential therapeutic applications. Int J Cancer 127: 1741-1747, 2010.
$35 \mathrm{Lu}$ Y, Zhang TF, Shi Y, Zhou HW, Chen Q, Wei BY, Wang X, Yang TX, Chinn YE, Kang J and Fu CY: PFR peptide, one of the antimicrobial peptides identified from the derivatives of lactoferrin, induces necrosis in leukemia cells. Sci Rep 6: 20823, 2016.

36 Lehmann J, Retz M, Sidhu SS, Suttmann H, Sell M, Paulsen F, Harder J, Unteregger G and Stockle M: Antitumor activity of the antimicrobial peptide Magainin II against bladder cancer cell lines. Eur Urol 50: 141-147, 2006.

37 Elmore S: Apoptosis: A review of programmed cell death. Toxicol Pathol 35: 495-516, 2007.

38 Wang QQ, Zhang LL, Yuan XD, Ou Y, Zhu XH, Cheng ZZ, Zhang PS, Wu XY, Meng Y and Zhang LP: The relationship between the BCL-2/BAX proteins and the mitochondria-mediated apoptosis pathway in the differentiation of adipose-derived stromal cells into neurons. PLoS One 11: e0163327, 2016.

39 Gottlieb E, Armour SM, Harris MH and Thompson CB: Mitochondrial membrane potential regulates matrix configuration and cytochrome $c$ release during apoptosis. Cell Death Differ 10: 709-717, 2003.

40 Martinou JC and Youle RJ: Mitochondria in apoptosis: BCL-2 family members and mitochondrial dynamics. Dev Cell 21: 92101, 2011.

41 Zhang MZ, Zheng J, Nussinov R and Ma BY: Release of cytochrome $c$ from bax pores at the mitochondrial membrane. Sci Rep 7: 2635, 2017.

42 Patathananone S, Thammasirirak S, Daduang J, Chung JG, Temsiripong $\mathrm{Y}$ and Daduang $\mathrm{S}$ : Bioactive compounds from crocodile (Crocodylus siamensis) white blood cells induced apoptotic cell death in HeLa cells. Environ Toxicol 31: 986-997, 2016.

43 Wei L, Jin X, Cao Z and Li W: Evodiamine induces extrinsic and intrinsic apoptosis of ovarian cancer cells via the mitogen-activated protein kinase/phosphatidylinositol-3-kinase/protein kinase B signaling pathways. J Tradit Chin Med 36: 353-359, 2016. 